\title{
Alternativas dentro e além do capitalismo: rumo a um socialismo social ${ }^{*}$
}

\author{
Alternatives within and beyond capitalism: \\ towards a social socialism
}

\section{Erik Olin Wright**}

Presidente da American Sociological Association (ASA), Departamento de Sociologia, Universidade de Wisconsin-Madison.

e-mail:wright@ssc.wisc.edu

**autor correspondente
Recebido: 04/04/2012

Aceito: 01/06/2012
RESUMO $\mathrm{O}$ artigo propõe uma nova forma de se pensar alternativas ao capitalismo, fundamentada em múltiplas configurações de poder que promovam justiça social e democracia. O pressuposto teórico é que todo sistema econômico se estrutura como um híbrido, em que interagem o poder econômico, o poder estatal e o poder social. O capitalismo, isto é, um sistema econômico que se fundamenta na apropriação privada dos meios de produção e no controle da atividade econômica pelo poder econômico, coexiste com elementos socialistas. Apresenta-se uma série de configurações visuais que ilustra essa coexistência. Pensar uma alternativa socialista ao capitalismo é, portanto, empoderar os elementos socialistas e, para tal, discutem-se lógicas de transformação social que levam a esse empoderamento.

PALAVRAS-Chave Capitalismo; Socialismo; Poder; Transformação social.

ABSTRACT The paper proposes a new way of thinking about alternatives to capitalism, which relies on multiple configurations of power that promote social justice and democracy. The theoretical assumption is that all economic systems are structured as hybrids, where the economic power, state power and social power interact. Capitalism, defined as an economic system that is based on private ownership of the means of production and economic-power control of the economic activity, can coexist with socialist elements. The piece presents a series of visual configurations that illustrate such coexistence. To envision a socialist alternative to capitalism is, therefore, to empower socialist elements; in that respect, logics of social transformation that lead to this empowerment are discussed. KEYwords Capitalism; Socialism; Power; Social transformation.

\footnotetext{
*Este artigo segue reflexões desenvolvidas em Wright $(2006,2010)$. Tradução do inglês por João Alexandre Peschanski.
} 
Durante a maior parte do século 20, os críticos e defensores do capitalismo acreditaram que um "outro mundo era possível". A alternativa foi geralmente chamada "socialismo". Enquanto a direita condenava o socialismo por violar direitos individuais à propriedade privada e desencadear formas monstruosas de opressão estatal e a esquerda o via como a possibilidade de novas perspectivas de igualdade social, liberdade real e desenvolvimento dos potenciais humanos, os dois campos acreditavam que uma alternativa fundamental ao capitalismo era possível. Isso era especialmente importante para a esquerda. Apesar dos intensos debates em torno dos vários significados de socialismo e as duras críticas da esquerda democrática ao "socialismo realmente existente", a ideia de socialismo garantiu um quadro amplo para a política de esquerda, reunindo a crítica ao capitalismo e uma visão da vida e instituições que o superavam.

As coisas mudaram. Agora, no início do século 21, o projeto socialista não tem mais muita credibilidade política. Isto não se deve ao fato de as pessoas virem universalmente o capitalismo como uma ordem social benigna na qual a humanidade pode florescer. $\mathrm{Na}$ verdade vivemos em um período em que muitas das críticas socialistas tradicionais ao capitalismo parecem mais apropriadas do que nunca: a instabilidade e crises econômicas deterioram sistematicamente a vida de massas de pessoas; a desigualdade, a polarização econômica e a insegurança no trabalho têm se aprofundado em muitos países desenvolvidos economicamente; o capital tornou-se cada vez mais volátil, movendo-se em todo o mundo e prejudicando seriamente a capacidade democrática dos Estados e das comunidades; corporações gigantes dominam os meios de comunicação e a produção cultural; o mercado aparece como uma lei da natureza incontrolável pela ação humana; a política está cada vez mais dominada pelo dinheiro e não responde às preocupações e inquietações das pessoas comuns. A necessidade de uma alternativa dinâmica ao capitalismo é maior do que nunca. No entanto, os arranjos institucionais específicos que são geralmente associados com o socialismo são vistos como incapazes de cumprir o que se dispõem a fazer. Em vez de ser visto como uma ameaça ao capitalismo, falar de socialismo parece hoje um sonho utópico arcaico ou, talvez, ainda pior: um desvio na pauta dos assuntos solucionáveis no mundo real.

O desaparecimento do socialismo como uma visão emancipatória representa um problema para a esquerda. Não é que a esquerda política nos Estados Unidos e em outros lugares não tem boas idéias para mudanças sociais e políticas públicas que melhorariam a vida da maioria das pessoas, mas essas propostas não estão organizadas em um todo coerente, de tal modo a tornar-se um ideal atrativo. Sem uma concepção de alternativa sistêmica ao capitalismo é difícil distinguir reformas políticas que vão na direção de transformações mais fundamentais daquelas que, embora talvez sejam desejáveis, não vão nessa direção; e também é difícil ver as conexões e compreender as tensões entre os muitos tipos diferentes de propostas progressistas que podem estar sendo discutidas a qualquer momento. Repensar e revigorar a idéia de socialismo podem ajudar a resolver esses problemas.

No que segue, começarei com uma discussão breve dos fundamentos morais e empíricos da crítica ao capitalismo. Afinal, a menos que tal crítica seja bem fundamentada há pouco sentido em se preocupar com uma alternativa. Daí, desenvolverei os elementos centrais de um quadro geral para pensar o socialismo como uma alternativa ao capitalismo. O âmago desse quadro envolve levar a sério a palavra "social" em socialismo. O trabalho acabará com uma discussão do problema da transformação -- o que fazer para ir daqui para lá.

\section{Fundamentos da Crítica ao Capitalismo}

Elaborar bases normativas para a crítica de instituições existentes é, claro, algo controverso. Especificar tais fundamentos é importante porque não só constituem critérios críticos que podemos utilizar para avaliar as instituições existentes, mas também porque permitem avaliar as propostas e experiências de alternativas emancipatórias. Os socialistas não foram sempre claros em relação a esses critérios. Na verdade, dentro da tradição marxista houve até uma certa aversão a expô-los, considerando que as preocupações morais em torno de justiça social eram principalmente cobertas ideológicas sobre a questão dos interesses ${ }^{1}$.

\footnotetext{
Os marxistas afirmaram frequentemente que o socialismo era desejável porque era do interesse dos trabalhadores, não porque satisfazia qualquer critério moral de justiça. A preocupação com os interesses foi sustentada pela crença de que as leis de movimento do capitalismo eram tão autodestrutivas que, eventualmente, o capitalismo seria tão prejudicial e insustentável, que os interesses ligados a sua perpetuação se tornariam irrelevantes na prática -- virtualmente todos teriam interesse na alternativa. Há duas razões principais pelas quais eu sinto que essa afirmação não é satisfatória. Primeiro, sabemos que as pessoas são muitas vezes profundamente motivadas por preocupações morais, assim esclarecer a crítica moral ao capitalismo e a defesa do socialismo é parte do fortalecimento dos compromissos gerais com a transformação. Em segundo lugar, o argumento puramente baseado em interesses contra o capitalismo não é realmente mais claro do que o argumento baseado na justiça social. Atores dentro do capitalismo têm interesses complexos e contraditórios no que diz respeito ao problema da transformação, por vários motivos: as estruturas de classe não são polarizadas, muitas pessoas ocupam o que chamei de posições contraditórias dentro das relações de classe; os custos previstos na transformação fazem com que os interesses materiais nas transições se tornem ambíguos; a incerteza em torno da estabilidade e das conseqüências involuntárias das alternativas acentuam ainda mais as ambiguidades em torno dos interesses materiais da maioria das pessoas.
} 
Implícitos em boa parte da crítica socialista do capitalismo estão dois princípios fundamentais -- um princípio igualitário de justiça social e um princípio de empoderamento democrático radical. Formulo-os da seguinte forma:

- Justiça social: Numa sociedade justa, todas as pessoas teriam no geral acesso igual ao meios sociais materiais necessários para viver uma vida próspera. Há três ideias centrais nessa formulação. Em primeiro lugar, o bem supremo do princípio é a prosperidade humana [human flourishing]. Há uma variedade de termos interligados que é usada nas discussões sobre os ideais do igualitarismo: bem-estar, satisfação, felicidade e prosperidade. Em termos práticos, provavelmente não importa qual é usado, mas a prosperidade humana me parece menos vulnerável a uma interpretação puramente subjetiva. Em segundo lugar, a noção igualitária da justiça se vincula à ideia de igualdade de acesso, não igualdade de oportunidades. (A igualdade de oportunidades tem três problemas: primeiro, é consistente com uma loteria; segundo, não se atem à desigualdade dos resultados - a igualdade de oportunidades para estar saciado ou morrer de fome ainda é igualdade de oportunidades; e, terceiro, é consistente com o que se chama "a casa inicial da igualdade", uma visão muito punitiva em relação às pessoas que não conseguem tirar vantagem das oportunidades no início de suas vidas. A igualdade de acesso às condições para viver uma vida próspera evita esses problemas.) Por fim, o princípio da justiça social refere-se às condições tanto materiais quanto sociais necessárias para prosperar, não apenas às condições materiais. Isso significa que, na medida em que afetam a prosperidade humana, as questões de reconhecimento, estigma e exclusão social são questões da justiça social, juntamente com as preocupações mais convencionais do acesso aos recursos materiais.

- Democracia: Numa sociedade plenamente democrática, todas as pessoas teriam no geral acesso igual aos meios necessários para participar de forma significativa das decisões sobre as coisas que afetam suas vidas. Isso inclui tanto a liberdade dos indivíduos de fazerem escolhas que afetam suas próprias vidas como pessoas específicas quanto sua capacidade de participar de decisões coletivas que afetam suas vidas como membros de uma comunidade mais ampla. A liberdade individual e a democracia coletiva estão, portanto, fundamentadas no mesmo princípio de base: as pessoas deveram ter o máximo de controle possível sobre as coisas que afetam suas vidas.
Juntos, esses dois princípios podem ser chamados de igualitarismo democrático radical.

A plena realização desses ideais democráticos igualitários é necessariamente anticapitalista, pois o capitalismo intrinsecamente obstrui os dois princípios normativos ${ }^{2}$. As profundas desigualdades de riqueza e renda inerentes aos mercados capitalistas, juntamente com as muitas formas de externalidades negativas e fracassos de ação coletiva das economias capitalistas -- destruição ambiental, erosão da comunidade com a fuga de capitais, insegurança econômica gerada por crises, oferta insuficiente de todos os tipos de bens públicos etc. --, obstruem a igualdade de acesso das pessoas às condições sociais e materiais necessárias para viver uma vida próspera. A realização do princípio democrático é sistematicamente prejudicada pelas concentrações de riqueza que geram desigualdade no acesso ao poder político e pela remoção do controle coletivo de um vasto conjunto de decisões econômicas capitais que afetam nossas vidas, dando a proprietários privados o poder direto sobre essas decisões. Até a liberdade individual, apontada como a grande virtude do capitalismo, está seriamente prejudicada por características comuns das economias capitalistas: a organização hierárquica das empresas capitalistas priva os trabalhadores de autonomia e autogoverno no local de trabalho e as privações da pobreza bloqueiam a liberdade real das pessoas. Estes não são subprodutos circunstanciais do funcionamento do capitalismo; são inerentes a seus processos centrais. Levar a sério os princípios igualitários democráticos exige que se vá além do capitalismo. A pergunta que surge então é qual a melhor forma de teorizar a alternativa que melhor nos permita realizar os princípios igualitários democráticos.

\section{Um Quadro Geral de Análise}

Tanto a socialdemocracia quanto o socialismo contêm a palavra "social", mas geralmente o termo é invocado de uma forma solta e mal-definida. Supõe-se que faz referência a um programa político comprometido com o bem-estar geral da sociedade, não aos interesses estreitos de algumas elites. Às vezes, especialmente nas versões mais radicais do discurso socialista, a "propriedade social" dos meios de produção é invocada em contraste com a "propriedade privada", mas na prática isso geralmente quer dizer propriedade estatal e o termo social acaba tendo relativamente pouca valia analítica na elaboração de programas políticos. O que vou discutir é que o

\footnotetext{
${ }^{2}$ Para uma discussão mais aprofundada, cf. Wright (2010: cap. 3).
} 
social na socialdemocracia e no socialismo pode ser usado para identificar um conjunto de princípios e visões de mudança que diferencia o socialismo e a socialdemocracia tanto do projeto capitalista de organização econômica quanto do que poderia ser chamado de uma resposta puramente estatal para o capitalismo. Tais princípios giram em torno do que vou chamar de "empoderamento social". Isso, por sua vez, sugere uma maneira de pensar sobre uma gama de possibilidades futuras para o socialismo à qual geralmente não foi dado um lugar central na política socialista.

No centro da análise está um quadro centrado no poder para a compreensão capitalismo e suas alternativas. Poder é um conceito especialmente evasivo e controvertido na teoria social, muitas vezes incorporado em formulações opacas, o que torna muito difícil seu uso em discussões concretas sobre instituições e sua transformação. Aqui, vou adotar um conceito deliberadamente mínimo de poder: o poder é a capacidade de fazer coisas no mundo, produzir efeitos. Isto é o que poderia ser chamado de uma noção de poder "centrada no ator": as pessoas, tanto individual quanto coletivamente, usam o poder para realizar coisas.

Com essa definição ampla de poder, pode-se distinguir três tipos de poder que são empregados dentro de sistemas econômicos: o poder econômico, enraizado no controle sobre o uso de recursos econômicos; o poder estatal, enraizado no controle sobre a tomada de decisões e o cumprimento de regras sobre o território; e o que vou chamar de poder social, enraizado na capacidade de mobilizar as pessoas para ações coletivas voluntárias e cooperativas. Expresso como um slogan mnemônico, pode-se levar pessoas a fazerem coisas ao suborná-las, coagindo-as ou persuadindo-as. Cada sistema econômico envolve as três formas de poder, ligadas de maneiras diferentes.

No que corresponde a essas três formas de poder, pode-se distinguir três tipos ideais de estruturas econômicas -- capitalismo, estatismo e socialismo --, que diferem no modo como se dá a conexão entre as formas de propriedade sobre os meios de produção e de poder sobre a atividade econômica (ou seja, investimentos, produção e distribuição de bens e serviços):

- O capitalismo é uma estrutura econômica na qual os meios de produção são apropriados de modo privado e a atividade econômica é controlada pelo exercício do poder econômico.

- O estatismo é uma estrutura econômica na qual os meios de produção são apropriados pelo Estado e a atividade econômica é controlada pelo exercício do poder estatal. Agentes do Estado controlam o processo de investimento e produção por meio de algum tipo de mecanismo administrativo estatal.

- O socialismo é uma estrutura econômica na qual os meios de produção são apropriados socialmente ${ }^{3} \mathrm{e}$ a atividade econômica é controlada pelo exercício do "poder social". Isso equivale a dizer que a economia é democrática.

Essas três formas de estrutura econômica nunca existem no mundo em formas puras, mas estão sempre combinadas de formas complexas. Elas são híbridos, que variam de acordo com o modo como as diferentes formas de poder interagem. Chamar uma economia de "capitalista" é, portanto, um atalho para uma expressão mais complicada, "um híbrido que combina relações econômicas capitalistas, estatistas e socialistas dentro do qual as relações capitalistas são dominantes". A ideia de um híbrido estrutural pode ser usado para analisar qualquer unidade de análise -- empresas, setores, economias regionais, economias nacionais e até mesmo a economia global. A possibilidade do socialismo, portanto, depende de nossa capacidade de ampliar e aprofundar o componente socialista do híbrido e enfraquecer os componentes capitalista e estatista.

Essa maneira de pensar sobre os sistemas econômicos significa abandonar uma simples noção binária do capitalismo contra o socialismo. Uma estrutura econômica pode ser mais ou menos capitalista, mais ou menos socialista, mais ou menos estatista. É uma questão empírica importante, mas não resolvida, saber quão estáveis podem ser diferentes tipos de híbridos. Do ponto de vista marxista tradicional, qualquer híbrido capitalista, com significativos elementos socialistas, é inerentemente instável. O equilíbrio só pode ser estável -- para usar uma expressão de economistas -- quando o socialismo é inequivocamente dominante ou quando

\footnotetext{
As ideias de propriedade privada e propriedade estatal dos meios de produção é familiar, mas o que significa "propriedade social"? Isto é menos familiar e menos claro. A propriedade social dos meios de produção significa que a propriedade que gera renda é apropriada em comum por todos os envolvidos na atividade econômica interdependente que usa os meios de produção. "Propriedade comum" significa que todos os envolvidos nessa atividade econômica interdependente têm o direito coletivo à receita líquida gerada pela utilização dos meios de produção e o direito coletivo de se desfazer da propriedade que gera essa renda. Isso não implica necessariamente que a renda líquida é simplesmente dividida igualmente entre todos, apesar de isso poder ser uma expressão do princípio de propriedade comum. A propriedade comum significa que as pessoas coletivamente têm o direito de decidir sobre os fins em relação aos quais os meios de produção são usados e sobre a distribuição do excedente social -- a renda líquida gerada pelo uso dos meios de produção -- e isso é consistente com uma ampla gama de alocações reais. A propriedade é, assim, num sentido, um subconjunto de todas as relações de poder sobre os meios de produção. Para uma discussão mais ampla do conceito de propriedade social, ver Wright (2010: 113-117).
} 
o capitalismo é inequivocamente dominante e, no máximo, os elementos socialistas preenchem pequenos nichos no sistema econômico de tal forma a ser funcional para o capitalismo. Uma visão alternativa é que pode haver múltiplos equilíbrios estáveis envolvendo todas as três formas econômicas e que é até mesmo possível haver um equilíbrio estável em que não haja qualquer dominação entre elas. Para uma configuração qualquer ser estável é preciso que haja um conjunto complexo de fatores históricos e políticos circunstanciais e isso faz com que seja impossível fazer quaisquer proposições gerais e abstratas sobre o que realmente é possível.

Para os efeitos deste artigo, continuo agnóstico em relação ao problema da estabilidade de diferentes formas híbridas de estrutura econômica. Vou me concentrar, ao invés, na questão teórica das formas alternativas em que podemos conceituar o aprofundamento do componente socialista dos híbridos. Vou me referir a isso como o problema das configurações estruturais do empoderamento social.

\section{Um Vocabulário Visual}

Para explorar o problema do aprofundamento do componente socialista em sistemas econômicos híbridos, torna-se útil representar visualmente diferentes padrões de interconexão entre as três formas de poder dentro dos sistemas econômicos. $\mathrm{O}$ vocabulário visual que utilizo para este fim está ilustrado na Figura 1.

As setas na Figura 1 indicam a direção de influência de uma forma de poder sobre outra; a largura das setas indica a intensidade da relação. Assim, na primeira ilustração na Figura 1, o poder estatal está subordinado ao poder social. Isto é o que convencionalmente se entende por democracia política como "governo pelo povo": as pessoas voluntariamente formam associações -- notadamente, partidos políticos -- com a finalidade de controlar o uso do poder estatal por meio do mecanismo institucional das eleições. Numa democracia, o poder estatal ainda é importante -- por que ter uma democracia se o Estado não tem capacidade de fazer qualquer coisa? --, mas esse poder não é exercido de forma autônoma pelos agentes públicos; está subordinado ao poder social.

$\mathrm{Na}$ segunda ilustração, o poder econômico subordina o poder social. O uso desenfreado de doações feitas por corporações e pelos ricos para financiar os partidos políticos nos Estados Unidos é um exemplo disso. Os partidos políticos ainda importam -- eles são os veículos para a seleção de representantes do Estado, que exercem diretamente o poder estatal --, mas o poder social mobilizado pelos partidos políticos é, em si, subordinado ao exercício do poder econômico. A filantropia de corporações e ricos para financiar associações da sociedade civil é um outro exemplo: as associações podem mobilizar uma grande quantidade de participação voluntária, mas sua autonomia de ação é muito limitada por sua ligação ao poder econômico.

Essas configurações podem ser conectadas em redes de relações de poder, como na terceira ilustração: nesse caso, a influência das corporações sobre o poder do Estado ocorre pela subordinação dos partidos políticos. Finalmente, na quarta ilustração, o poder social subordina o poder econômico pela mediação do poder estatal. Este é o ideal da socialdemocracia: o Estado efetivamente regula o comportamento das empresas capitalistas, mas é, ele mesmo, democraticamente subordinado ao poder social.

A Figura 2 ilustra as diferentes configurações agregadas de formas de poder num híbrido econômico predominantemente capitalista e num híbrido econômico predominantemente socialista. Nesses diagramas, as setas estão todas direcionadas à explicação do controle sobre a atividade econômica: investimentos, produção e distribuição de bens e serviços. Na imagem do empoderamento capitalista, tanto o poder social quanto o poder estatal estão subordinados ao poder econômico em termos do controle sobre a atividade econômica; no caso do empoderamento socialista, o poder econômico e o poder estatal estão subordinados ao poder social.

\section{Configurações do Empoderamento Socialista: Elementos para Construir um Híbrido Socialista}

O propósito básico para o qual uso as representações esquemáticas é para diferenciar as configurações mais importantes do empoderamento social. Diferentes tipos de políticas progressistas, inovações e propostas institucionais, estratégias e reformas podem ser localizados dentro dessas várias configurações. Sete dessas configurações são particularmente importantes: 1. socialismo estatista; 2. regulação estatista socialdemocrata; 3 . democracia associativa; 4. capitalismo social; 5. a economia social principal; 6. a economia de mercado cooperativa; e 7. socialismo participativo. Vou discutir cada uma delas brevemente.

\section{Socialismo Estatista}

A configuração na Figura 3 corresponde à definição clássica de socialismo na qual o poder social controla a atividade econômica por meio do Estado. A economia 
Os três tipos de poder:

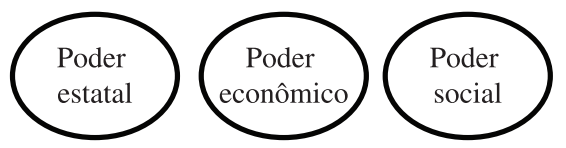

Interação das formas de poder:

Força e autonomia do poder:

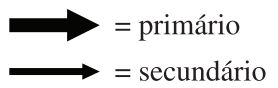

Ilustrações

1. Democracia convencional

2. Controle dos partidos

por corporações
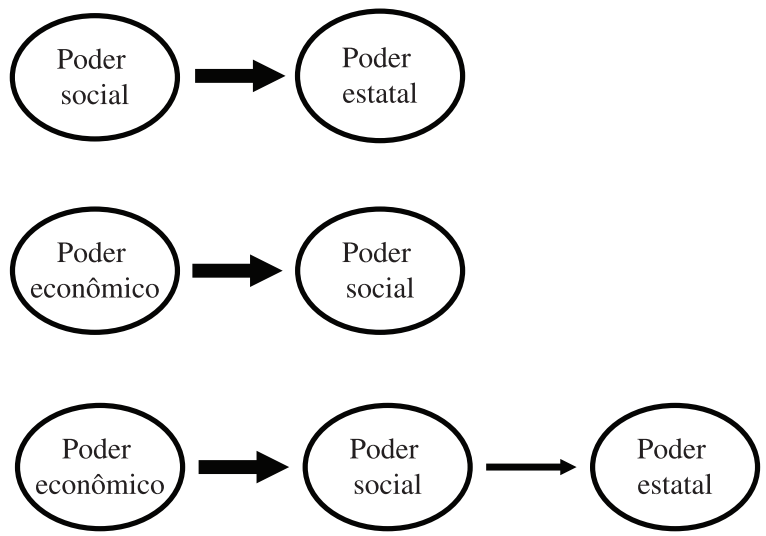

3. Controle do poder estatal por

corporações via partidos

4. Controle social do poder econômico via regulação estatal democrática do capital

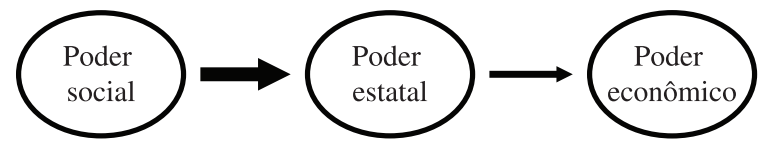

Figura 1. Representação visual das configurações de poder.

é controlada diretamente pelo exercício do poder estatal -- através, por exemplo, da propriedade estatal e do controle sobre os altos comandos da economia -- e, ao mesmo tempo, o poder estatal é subordinado ao poder social ao prestar contas democraticamente às pessoas. É a configuração que estava no centro das ideias marxistas tradicionais de socialismo revolucionário. Não foi assim, naturalmente, que se deram as revoluções que ocorreram em nome do socialismo no século 20 . Uma vez que o poder dos partidos revolucionários foi consolidado sob a forma do Estado de partido único, o "socialismo realmente existente" tornou-se uma forma de estatismo autoritário em que, como ilustrado na Figura 4, tanto o poder social na sociedade civil quanto o poder econômico foram subordinados ao poder estatal.

\section{Socialdemocracia I: Regulação Estatista Socialdemocrata}

Na segunda configuração, ilustrada na Figura 5, o poder social regula a economia através da mediação tanto do poder estatal quanto do poder econômico. Esta é uma parte essencial da socialdemocracia. O poder econômico capitalista controla diretamente a atividade econômica -- os capitalistas continuam a fazer investimentos, contratar administradores, organizar o processo de trabalho etc. --, mas esse poder é regulado pelo poder estatal, que por sua vez é subordinado ao poder social. Através de uma transitividade de relações de poder, isso significa que o poder social exerce um controle regulador sobre o exercício do poder econômico. Essas formas de regulação do capital que melhoram as condições de trabalho e a segurança no trabalho, além de proteger 
Configurações do empoderamento capitalista

Configurações do empoderamento $\underline{\text { socialista }}$

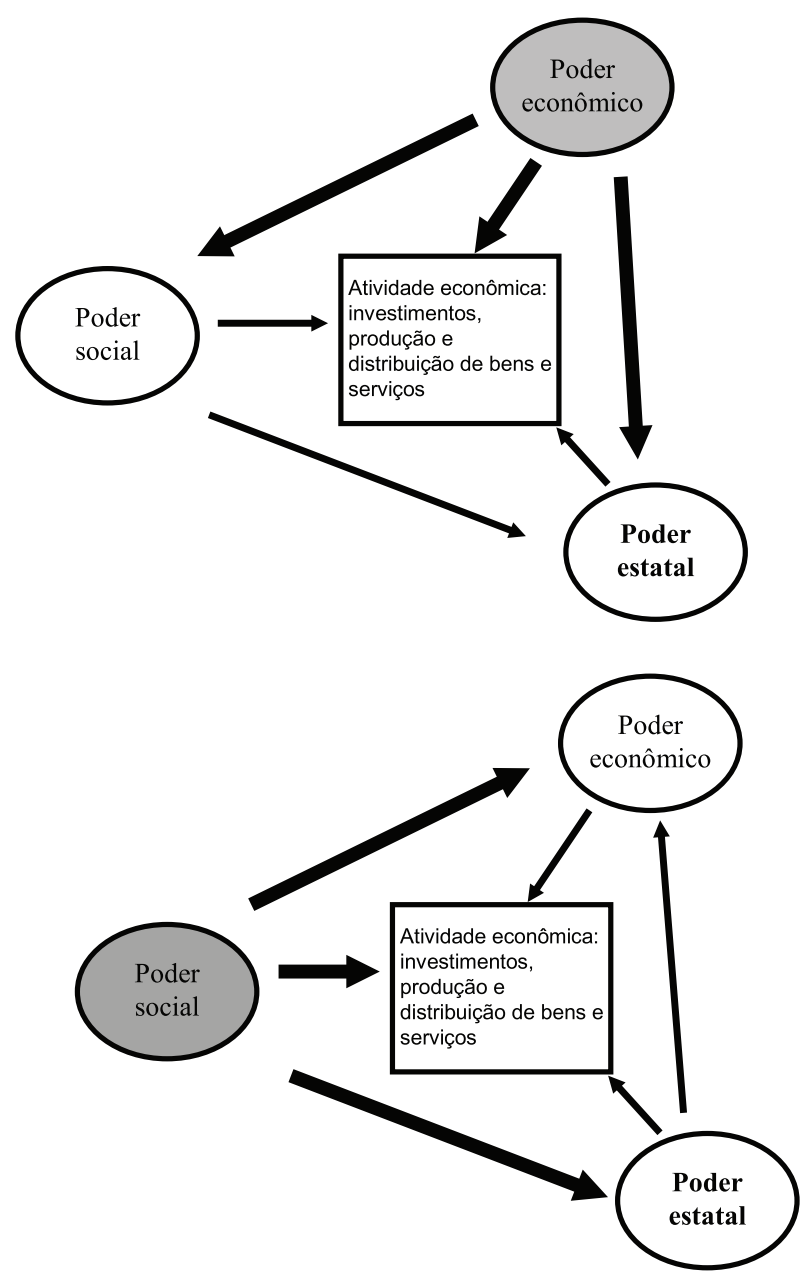

Figura 2. Configurações agregadas do empoderamento capitalista e do empoderamento socialista.

o meio ambiente, muitas vezes refletem esse tipo de imposição democrática de restrições.

A regulação estatal do poder econômico capitalista, no entanto, não precisa pressupor empoderamento social significativo. Como no caso do socialismo estatista, a questão aqui é a extensão e a profundidade de quanto o poder estatal é uma expressão genuína do empoderamento democrático da sociedade civil. Em sociedades capitalistas reais, muito do regulação econômica estatista está, na verdade, subordinado ao poder econômico, como ilustrado na Figura 6: na regulação estatista capitalista, o poder estatal regula o capital, mas de maneiras que respondem sistematicamente ao poder do próprio capital. Nos Estados Unidos, o grande envolvimento das associações de indústrias na definição das regras da regulação federal das companhias aéreas, energia, agricultura e outros setores é um exemplo disso. Talvez, de modo ainda mais marcante, a dependência estrutural do Estado na economia capitalista caracteriza essa configuração de relações de poder ${ }^{4}$.

\footnotetext{
${ }^{4}$ Grande parte da teoria do caráter capitalista do Estado capitalista desenvolvido no fim dos anos 1960 e nos anos 1970 pode ser interpretada como uma tentativa de explicar como, apesar da forma democrática do Estado, muito -- talvez a maioria -- da intervenção do Estado na economia capitalista está subordinado às necessidades do capital e não à vontade coletiva do povo, fazendo com que, nos termos deste artigo, seja uma expressão do poder econômico em vez do poder social. Esse argumento é particularmente bem formulada por Claus Offe (1974: 31-54) e Göran Therborn (1978).
} 


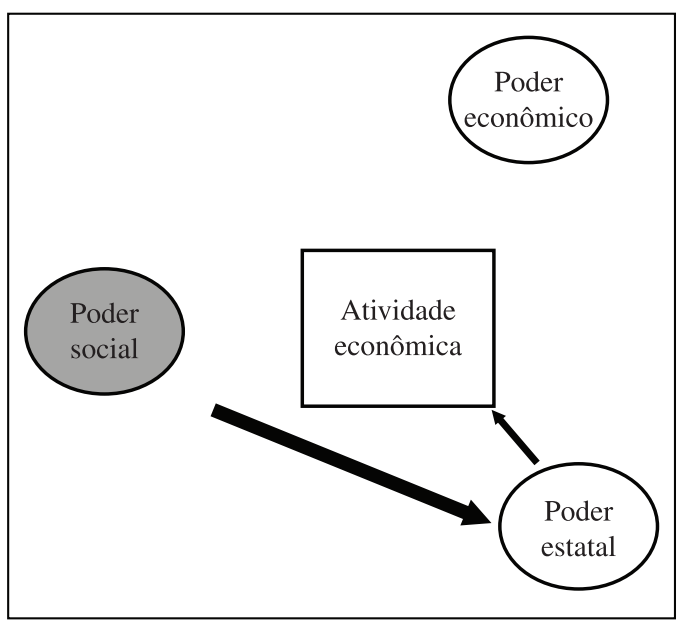

Figura 3. Socialismo estatista.

\section{Socialdemocracia II: Democracia Associativa}

Democracia associativa é um termo que abrange uma vasta gama de dispositivos institucionais pelos quais as associações coletivas da sociedade civil participam diretamente em vários tipos de atividades do governo, em geral juntamente com órgãos estatais (Figura 7). Sua forma mais familiar é, provavelmente, o arranjo tripartida neocorporativista em algumas sociedades socialdemocratas, como a Alemanha ou a Suécia, em que organizações de trabalhadores, associações de empregadores e Estado se reúnem para negociar vários tipos de regulamentos econômicos, especialmente aqueles que dizem respeito ao mercado de trabalho e às relações laborais. A democracia associativa pode ser estendida a muitos outros domínios, como conselhos de bacias hidrográficas, que reúnem associações cívicas. grupos ambientalistas, desenvolvedores e agências estatais de regulação dos ecossistemas, e conselhos de saúde, envolvendo associações médicas, organizações comunitárias e funcionários da saúde pública para planejar vários aspectos do sistema de saúde. Na medida em que as associações envolvidas são democráticas internamente e representativas dos interesses da sociedade civil e que o processo de tomada de decisão em que estão envolvidos é aberto e deliberativo, em vez de fortemente manipulado por elites e peloEstado, então a democracia associativa pode contribuir para o empoderamento social.

\section{A Economia Social I: 0 Capitalismo Social}

Vou usar o termo "economia social" para designar todas as configurações de empoderamento social dentro de uma economia em que o Estado não está

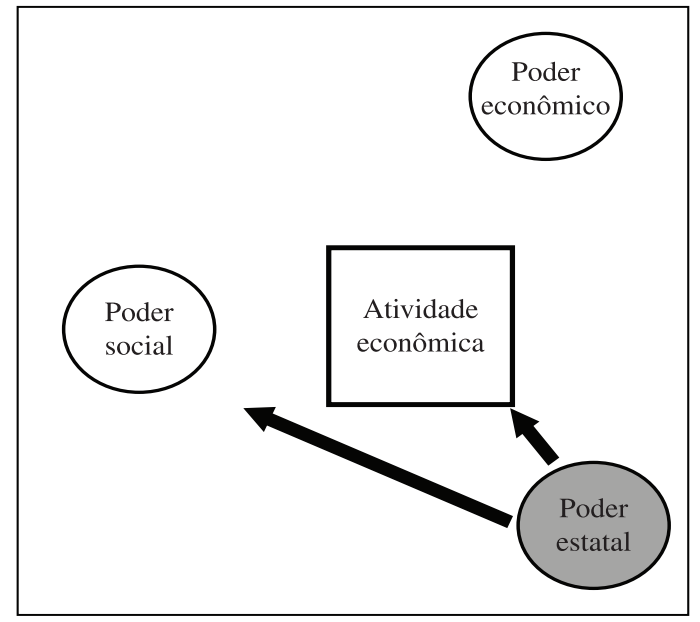

Figura 4. Uma configuração de empoderamento estatista: o estatismo autoritário.

diretamente envolvido ${ }^{5}$. A primeira configuração da economia social é o "capitalismo social". Esta não é uma expressão usual. Emprego-a para descrever uma configuração de poder em que as associações secundárias da sociedade civil, através de uma variedade de mecanismos, afetam diretamente a maneira como o poder econômico é usado (Figura 8). Por exemplo, os sindicatos muitas vezes controlam grandes fundos de pensão. Estes geralmente são regidos por normas de responsabilidade fiduciária que limitam severamente o potencial de utilização desses fundos para outros fins que não fornecer pensões seguras para os beneficiários. Mas essas regras poderiam ser alteradas, e os sindicatos poderiam exercer poder sobre as empresas através da gestão de tais fundos. Um exemplo é o que se conhece como "fundos de solidariedade" de alguns sindicatos no Canadá, especialmente Quebec. Nesses fundos, os sindicatos usam parte de seus fundos de pensão como uma participação particular em empresas capitalistas geograficamente enraizadas para influenciar diretamente as práticas e estratégias de desenvolvimento dessas empresas. Um sistema de fundos de solidariedade em que os sindicatos pudessem colocar representantes nos conselhos de administração das empresas e impor formas significativas de gestão participativa dentro delas

\footnotetext{
${ }^{5}$ Claro que, de certo modo, o Estado está sempre envolvido em todas as atividades econômicas, na medida em que impõe regras do jogo, cobra impostos etc. A questão aqui é que, na economia social, o Estado opera de modo relativamente passivo, no fundo em vez de na organização direta da atividade econômica e da regulação do poder econômico.
} 


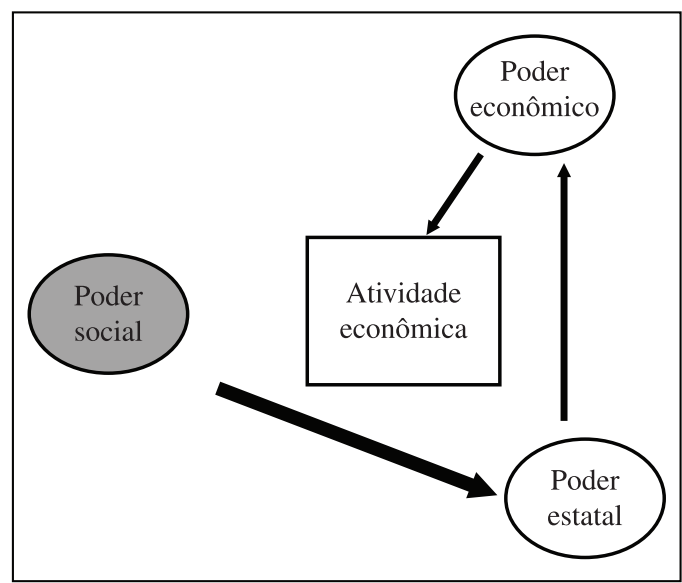

Figura 5. Socialdemocracia I: regulação estatista social democrata.

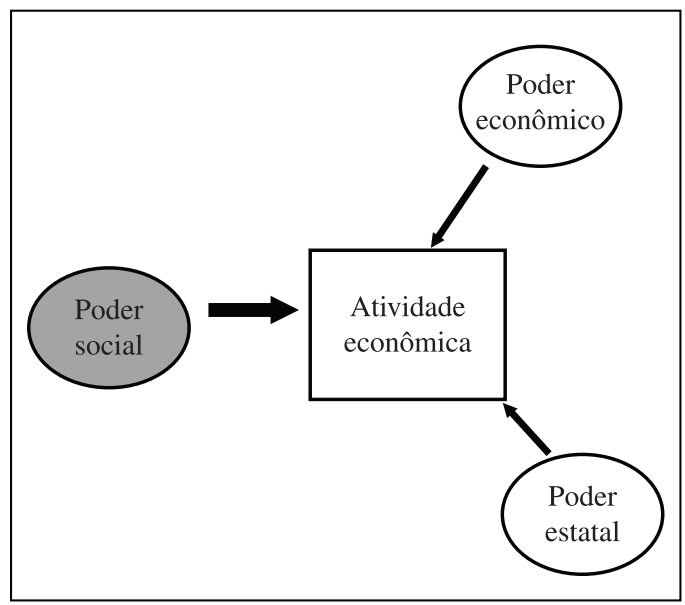

Figura 7. Socialdemocracia II: democracia associativa.

aprofundaria o caráter socialista dessa configuração de poder.

O simples fato de que o poder social tem um impacto sobre o poder econômico, no entanto, não significa que ele constitui uma forma de empoderamento social. $\mathrm{Na}$ Figura 9, o poder social afeta o exercício do poder econômico, mas ele faz isso de uma forma que é em si subordinado ao poder econômico. Um exemplo seriam as associações comerciais formadas pela cooperação voluntária de empresas capitalistas com o objetivo de definir padrões para seu ramo de atividade e de várias formas regular as diversas práticas das empresas. Esse tipo de autorregulação corporativa organizada de ramos de atividade constitui uma configuração de empoderamento capitalista, não de empoderamento socialista.

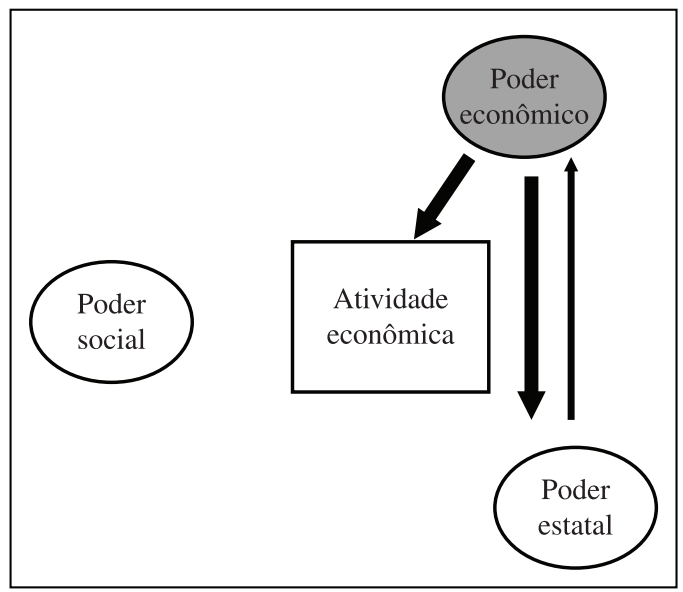

Figura 6. A configuração do empoderamento capitalista: a regulação estatista capitalista.

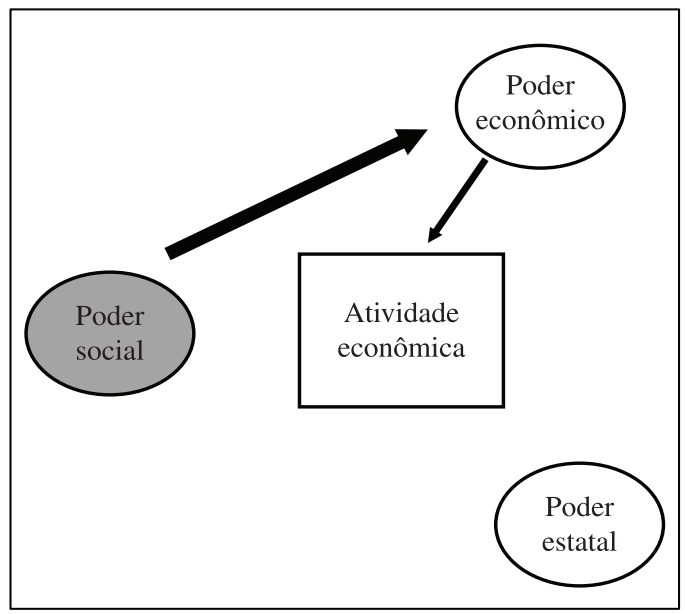

Figura 8. A economia social I: o capitalismo social.

\section{A Economia Social II: A Economia Social Principal}

A "a economia social principal" vai além do capitalismo social, constituindo uma forma alternativa de organizar diretamente a atividade econômica, que é distinta da produção de mercado capitalista, da produção organizada pelo Estado e da produção familiar (Figura 10). Sua principal característica é que a produção é organizada diretamente por coletividades para satisfazer as necessidades humanas, não estando sujeita à disciplina da maximização do lucro ou da racionalidade tecnocrática estatal. O Estado pode estar envolvido no financiamento dessas coletividades, mas não as organiza diretamente e não organiza os serviços que oferecem. O sistema de creches no Quebec é um bom exemplo. Em 2008, pais só pagavam sete dólares 


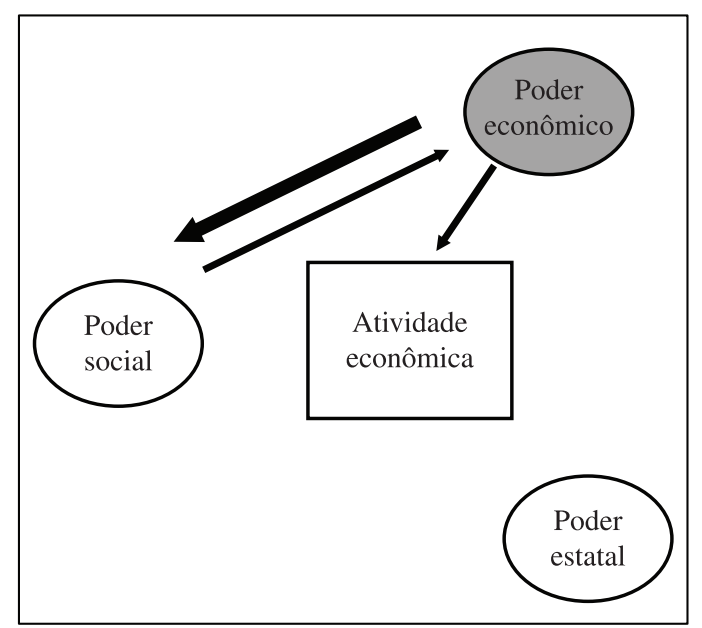

Figura 9. Uma configuração de empoderamento capitalista: a autorregulação corporativa organizada.

canadenses por dia para creches em tempo integral para crianças com idade pré-escolar, oferecidas por organizações comunitárias sem fins lucrativos, mas com subsídios do governo provincial para garantir que os prestadores do serviço eram pagos um salário digno. As creches eram geralmente organizadas como "cooperativas solidárias", uma forma organizacional governada por representantes eleitos dos funcionários, consumidores (os pais, nesse caso) e membros da comunidade. Outro exemplo marcante de economia social principal é a Wikipedia. A Wikipedia produz conhecimento e dissemina informações sem passar por mercados e sem o apoio do Estado; o financiamento provém em grande parte de doações de participantes e apoiadores. A produção dessa enciclopédia on-line, enorme e gratuita, com mais de 4 milhões de entradas em inglês, é feita inteiramente por trabalho voluntário, colaborando através de uma estrutura em rede complexa rede em condições extremamente abertas e igualitárias.

\section{A Economia Social III: A Economia de Mercado Cooperativa}

Numa firma cooperativa totalmente autogestionada numa economia capitalista o princípio igualitário de um voto para cada pessoa dentre todos os membros da empresa significa que as relações de poder dentro da empresa são baseadas na cooperação voluntária e na persuasão, não no poder econômico relativo das diferentes pessoas. Em conjunto controlam, por meios democráticos, o poder econômico representado pelo capital na empresa. E, se várias empresas cooperativas se unem em associações de cooperativas maiores -- talvez até mesmo numa cooperativa de cooperativas, oferecendo coletivamente financiamento, treinamento

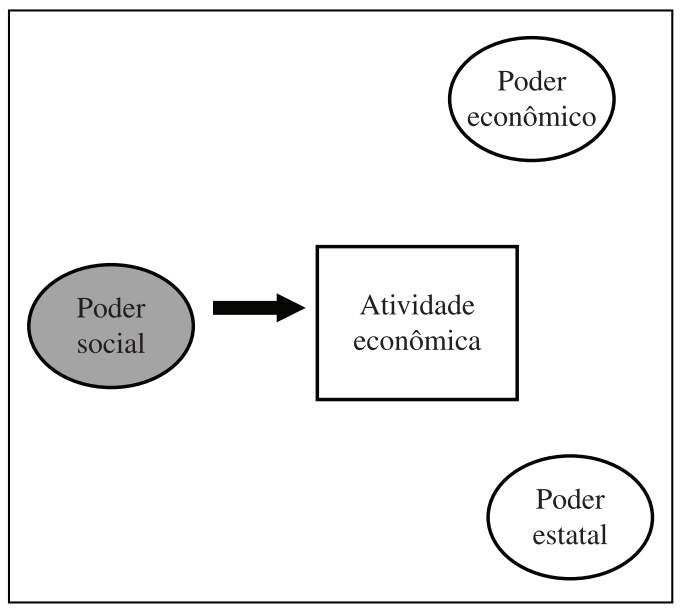

Figura 10. A economia social II: a economia social principal.

e outros tipos de suporte --, elas começam a transcender o caráter capitalista de seu ambiente econômico, constituindo uma economia de mercado cooperativa (Figura 11). A abrangência da cooperação nesse mercado estende o caráter social da propriedade nas empresas cooperativas individuais e faz com que a governança assuma mais um modelo definido por quem tem algum interesse nas questões discutidas, em que as empresas cooperativas são regidas por órgãos democráticos que representam todas as categorias de pessoas cujas vidas são afetadas pela atividade econômica das empresas. A grande Corporação Cooperativa Mondragón no País Basco, composta por cerca de 270 diferentes empresas autogestionadas, é um exemplo disso. Essas empresas continuam sendo uma forma econômica híbrida, combinando elementos capitalistas e socialistas, mas um híbrido em que o componente socialista tem um peso considerável.

\section{Socialismo Participativo}

A configuração final do empoderamento social combina economia social e socialismo estatista: o Estado e a sociedade civil organizam em conjunto e controlam vários tipos de produção de bens e serviços (Figura 12). No socialismo participativo, o papel do Estado é mais importante do que na economia social pura. O Estado não se limita a fornecer financiamento e definir os parâmetros; está também diretamente envolvido, de várias maneiras, na organização e produção da atividade econômica. Mas o socialismo participativo também é diferente do socialismo estatista, pois aqui o poder social não atua apenas pelos canais normais do controle democrático das políticas estaduais, mas diretamente dentro das próprias atividades produtivas. Um bom exemplo é o 


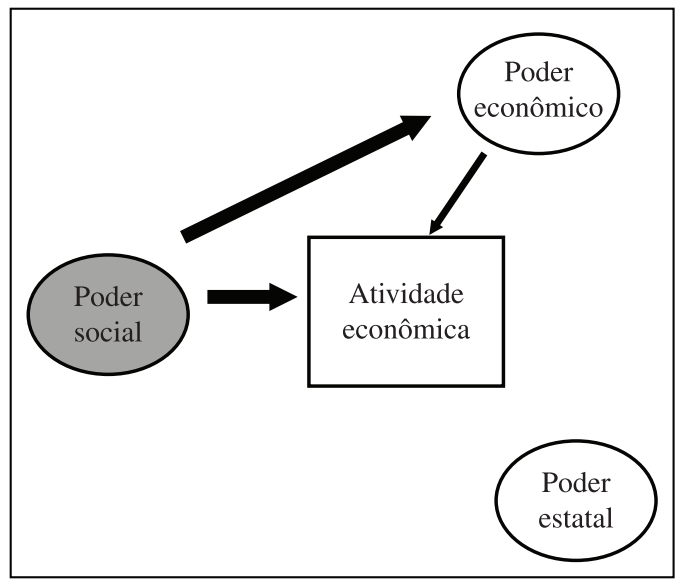

Figura 11. A economia social III: a economia de mercado cooperativa.

orçamento participativo no governo municipal, que começou na cidade brasileira de Porto Alegre em 1989 e, posteriormente, foi introduzido em muitos outros lugares no Brasil e em outros países. No orçamento participativo, os orçamentos municipais, especialmente a alocação de investimentos públicos para vários tipos de infra-estrutura, são criados por meio de um sistema de assembleias de bairro em que qualquer morador pode participar e decidir sobre prioridades orçamentárias e projetos específicos, parecido com o que ocorre nas reuniões populares da Nova Inglaterra. As assembleias de bairro, em seguida, escolhem delegados para participar de uma assembleia sobre o orçamento de toda a cidade, com a responsabilidade de produzir um orçamento coerente e integrado. Como esses orçamentos constituem alocações de recursos para a produção de infraestrutura para atender necessidades humanas, devem ser tratados como um aspecto da atividade econômica e, portanto, orçamentos participativos são uma forma de empoderamento social sobre a economia, não simplesmente uma forma de participação democrática no Estado .

\section{Unindo as Sete Configurações}

Conforme resumido na Figura 13, as diferentes configurações de empoderamento social que examinamos podem ser agrupadas em três grandes conjuntos, cada um correspondendo a diferentes tradições políticas de transformação socioeconômica: um conjunto socialista, um conjunto de economia social e um conjunto socialdemocrata. Esses conjuntos variam em relação ao papel que atribuem ao Estado e na medida em que tentam subordinar o

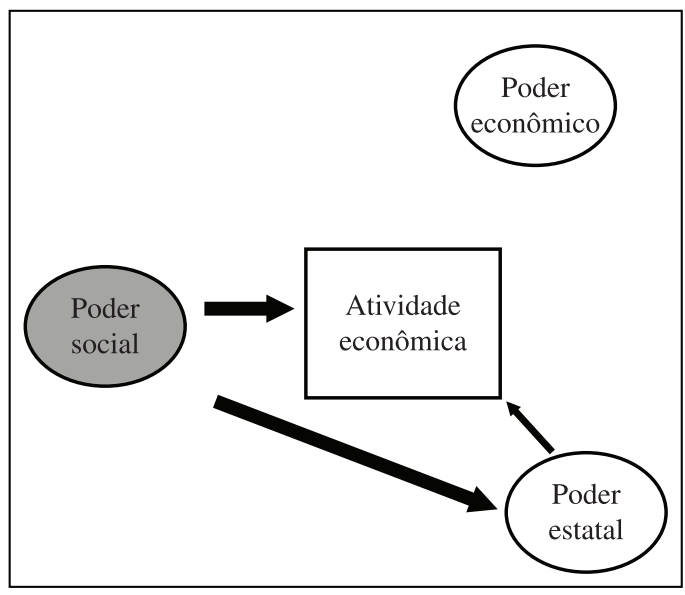

Figura 12. Socialismo participativo.

poder econômico capitalista, em vez de ignorá-lo. O que todas essas configurações têm em comum é a ideia de democratização do poder sobre a vida econômica, subordinando o poder econômico e o poder estatal ao poder social, enraizado na cooperação voluntária para a ação coletiva. Claro que o ideal do socialismo envolve muito mais do que isso. Igualdade e justiça social são também valores socialistas tradicionais fundamentais, aos quais hoje se deve adicionar a sustentabilidade ambiental. O que este modelo de socialismo salienta, no entanto, é que a realização de todos esses valores depende da transformação das relações de poder sobre a atividade econômica, no que diz respeito a como o poder social está diretamente envolvido na elaboração da atividade econômica e indiretamente pela democratização do Estado.

\section{Problema da Transformação}

Transformar o capitalismo em uma direção socialista significa democratizar a economia por meio das sete configurações resumidas na Figura 13. Nesse processo, a estrutura econômica continua a ser um híbrido que combina práticas e relações capitalistas, estatistas e socialistas, mas a dimensão socialista ganha peso e centralidade. Ampliar e aprofundar o poder social em qualquer uma dessas configurações podem ser razoavelmente compatível com a manutenção da dominação do capitalismo, mas, se for possível aumentar o poder social dentro de todas as configurações, o efeito cumulativo pode ser uma transformação qualitativa em que o socialismo se torna a forma dominante de relações dentro de um 


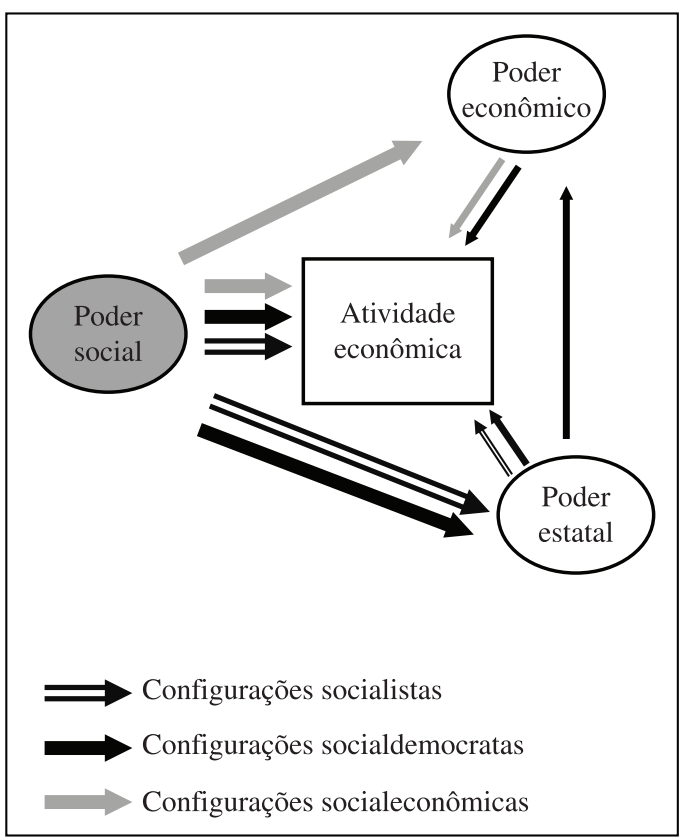

Figura 13. Configurações de empoderamento social reunidas

híbrido econômico complexo, subordinando tanto o capitalismo quanto o estatismo ${ }^{6}$.

É claro que isso é um grande "se". O ceticismo em relação ao socialismo na era moderna coloca-se, pelo menos, tanto no que diz respeito às perspectivas de desafiar o domínio das relações capitalistas quanto no que tange à viabilidade das instituições alternativas se elas pudessem ser criadas. O poder do capital parece tão grande que, se em algum momento, o poder social parecesse ameaçar sua dominação, seria implacavelmente atacado e enfraquecido. Um progresso real no avanço do projeto de democratizar a economia por essas configurações parece impossível enquanto o capitalismo for dominante. Por essa razão os anticapitalistas radicais muitas vezes sentiram que destruir de modo definitivo o poder do capital era uma condição prévia para um movimento significativo rumo ao socialismo, em vez de ser uma consequência importante desse movimento.

Marx tinha uma solução elegante para esse problema. Ele acreditava que, no longo prazo, o capitalismo destruiria suas próprias condições de

\footnotetext{
${ }^{6}$ Não é fácil especificar de modo rigoroso os critérios para que uma forma de relações sociais ser definida como "dominante" dentro de um híbrido econômico estrutural complexo. Adoto o que pode ser chamado de uma solução "funcionalista" a esse problema: o capitalismo é dominante dentro de um híbrido na medida em que estabelece os limites funcionais de compatibilidade dentro dos quais os outros elementos se adaptam e podem variar. Para uma discussão disso, cf. Wright (2010: 125-8).
}

existência: as leis do movimento e contradições do capitalismo, por fim, fariam dele um sistema cada vez mais frágil e vulnerável, em que a capacidade da classe dominante e seus aliados políticos de bloquear a transformação se tornaria progressivamente mais fraca ao longo do tempo. Eventualmente, o capitalismo se tornaria simplesmente insustentável. Esta era uma previsão forte, não simplesmente uma afirmação fraca sobre possibilidades futuras ${ }^{7}$. Isso não resolve o problema de como exatamente construir uma alternativa emancipatória ao capitalismo, mas pelo menos torna o problema de superar os obstáculos das relações de poder existentes menos assustador no longo prazo.

Poucas pessoas hoje -- mesmo aquelas que continuam a trabalhar dentro da tradição marxista de análise social e econômica -- estão convencidas de que o capitalismo se destruirá. O capitalismo pode estar propenso a crises e causar grande sofrimento no mundo, mas também tem uma enorme capacidade de bloquear efetivamente alternativas. O problema de sua transformação, pelo menos no mundo desenvolvido, portanto, não pode ser tratado como, principalmente, o problema da avaliação do momento exato em que o capitalismo, por meio de suas próprias contradições, torna-se tão fraco, caótico e é vulnerável que pode ser derrubado. Pelo contrário, o problema da transformação exige a compreensão das formas pelas quais as estratégias de transformação têm alguma perspectiva a longo prazo para levar à erosão das relações de poder capitalistas e a construção de alternativas socialistas.

Três lógicas estratégicas de transformação têm caracterizado a história da luta anticapitalista. Refiro-me a essas estratégias como ruptural, intersticial e simbiótica:

- Transformações rupturais vislumbram a criação de novas instituições emancipatórias através de uma ruptura com as instituições e estruturas sociais existentes. A imagem central é a de uma guerra em que finalmente a vitória depende da derrota decisiva do inimigo num confronto direto. $\mathrm{O}$ resultado da vitória é uma disjunção radical nas estruturas institucionais em que as instituições existentes são destruídas e novas são construídas de uma forma bastante rápida. Na maioria das versões, esse cenário revolucionário envolve a

\footnotetext{
Há muito debate sobre essa questão, mas, acredito, Marx era no geral determinista em relação à destruição do capitalismo. $\mathrm{O}$ capitalismo não podia, pensava, sobreviver continuamente dada a intensificação das contradições geradas por suas leis de movimento. Para uma discussão aprofundada da teoria do futuro do capitalismo e sua trajetória de autodestruição relevante ao problema do socialismo em Marx, cf. Wright (2010: cap. 4).
} 
tomada do poder, transformando rapidamente as estruturas estatais e, em seguida, usando esses novos aparelhos de poder estatal para destruir o poder da classe dominante dentro da economia.

- Transformações intersticiais buscam construir novas formas de empoderamento social nos nichos, espaços e margens da sociedade capitalista, muitas vezes onde não parecem representar qualquer ameaça imediata para as classes e elites dominantes. A visão de Proudhon de construir uma alternativa cooperativa ao capitalismo dentro do próprio capitalismo é uma versão do século 19 dessa perspectiva. As várias experiências da economia social de hoje também são exemplos disso. A ideia teórica central é que a construção de alternativas na prática, em todos os espaços em que isso for possível, serve tanto uma função ideológica fundamental, mostrando que formas alternativas de trabalho e vida são possíveis quanto, potencialmente, para corroer os obstáculos nos próprios espaços.

- Transformações simbióticas envolvem estratégias em que a expansão e aprofundamento das formas institucionais de empoderamento social popular resolvem simultaneamente alguns problemas práticos enfrentados pelas classes e elites dominantes. Isto é o que na década de 1970 foi chamado de "reformas não reformistas" -- reformas que simultaneamente tornam a vida melhor dentro do sistema econômico existente e expandem o potencial para futuros avanços do poder democrático.

Todas essas lógicas estratégicas têm, historicamente, um lugar dentro dos movimentos sociais e da política anticapitalista. As estratégias rupturais estão mais estreitamente associadas ao socialismo revolucionário e ao comunismo, as estratégias intersticiais, a algumas correntes do anarquismo e as estratégias simbióticas, à socialdemocracia. É fácil apresentar objeções a cada uma delas. As estratégias rupturais têm um apelo grandioso e romântico para os críticos do capitalismo, mas o registro histórico é bastante desanimador. Não há casos em que o socialismo, tal como foi definido aqui -- uma organização profundamente democrática e igualitária das relações de poder dentro de uma economia -- tenha sido o resultado de uma estratégia ruptural de transformação do capitalismo. As estratégias rupturais parecem, na prática, mais propensas a resultar no estatismo autoritário do que no socialismo democrático. As estratégias intersticiais podem produzir melhorias na vida das pessoas e bolsões de práticas mais igualitárias e democráticas, mas também não conseguiram em nenhum lugar corroer significativamente as relações de poder capitalistas. No que diz respeito às estratégias simbióticas, nos casos mais bem sucedidos da democracia social certamente levaram a um capitalismo mais humano, com menos pobreza, menos desigualdade, menos insegurança, mas o fizeram de forma a estabilizar o capitalismo e deixaram intactos os poderes centrais do capital. Todo avanço das estratégias simbióticas que pareciam potencialmente ameaçar os poderes centrais foi maciçamente resistido pelo capital. A reação dos capitalistas suecos às propostas de participação séria dos sindicatos no controle dos investimentos no fim dos anos 1970 é um dos exemplos mais bem conhecidos ${ }^{8}$. Estas são todas objeções razoáveis. Tomadas em conjunto, sugerem para muitas pessoas que transcender o capitalismo por algum tipo de estratégia coerente a longo prazo simplesmente não é possível.

O pessimismo é intelectualmente fácil, talvez até intelectualmente preguiçoso. Muitas vezes reflete uma simples extrapolação da experiência passada para o futuro. Nossas teorias do futuro, no entanto, são fracas demais para realmente fazer afirmações confiantes de que nós sabemos o que não pode acontecer. A orientação adequada para as estratégias de transformação social, portanto, é fazer as coisas agora que nos colocam numa posição melhor para fazer mais depois, trabalhar para criar as instituições e estruturas que aumentam, em vez de diminuir, as perspectivas de tirar vantagem de quaisquer oportunidades históricas que emerjam.

Nesses termos, acho que a melhor perspectiva é um pacote estratégico organizado principalmente em torno da interação entre as estratégias intersticiais e simbiótica, com aspectos episódicos de estratégia ruptural. Pelas estratégias intersticiais, ativistas e comunidades podem construir e fortalecer as instituições econômicas alternativas que incorporem princípios democráticos igualitários, onde isso for possível. As estratégias simbióticas, através do Estado, podem ajudar a abrir mais espaço para essas inovações intersticiais. As estratégias simbióticas podem expandir diretamente o espaço do poder social, por exemplo através de coisas tais como o orçamento participativo, e melhorar as condições para que iniciativas da economia social cresçam. A interação entre as estratégias intersticiais e simbiótica poderia, então, criar uma trajetória de aprofundamento dos elementos socialistas dentro do sistema híbrido capitalista.

As cooperativas de trabalhadores são um bom exemplo. Nas condições existentes, cooperativas de

\footnotetext{
${ }^{8}$ Cf. Wright (2010: 230-4).
} 
trabalhadores enfrentam obstáculos muito grandes para se tornarem um componente significativo das economias de mercado: os mercados de crédito são céticos em relação às empresas cujos donos são os trabalhadores; os trabalhadores são, compreensivelmente, avessos ao risco e relutantes em apostar suas poupanças em um empreendimento que tem baixa probabilidade de sucesso; as cooperativas enfrentam cadeias de suprimentos em que, por causa da escala, pagam custos mais elevados do que seus rivais capitalistas corporativos; e assim por diante. As estratégias simbióticas voltadas para políticas públicas poderiam resolver todas essas questões. Dado o potencial das cooperativas cujos donos são os trabalhadores de ajudarem a resolver os problemas de desemprego, de economias locais precárias e a deterioração das bases fiscais, novas regras para apoiar as cooperativas poderiam ganhar força política. Mesmo dentro da lógica das economias de mercado, as externalidades positivas e a promoção de bens públicos das cooperativas de trabalhadores apresentam uma justificação sólida para as subvenções públicas e planos de seguros para aumentar sua viabilidade. Essas políticas poderiam, ao longo do tempo, expandir o peso de uma economia de mercado cooperativa dentro do híbrido econômico capitalista mais geral.

Essa combinação de estratégias simbióticas e intersticiais não implica que o processo de transformação seguirá um caminho suave de cooperação iluminada entre as forças de classe conflitantes. O que está em jogo aqui é uma transformação das relações centrais de poder do capitalismo e isso ameaça no fim das contas os interesses dos capitalistas. As elites podem resignar-se a uma diminuição de seu poder, mas é improvável que elas graciosamente aceitem essa perspectiva. Enquanto as transformações simbióticas ajudam a resolver problemas dentro do capitalismo -- esta é uma das razões pelas quais eles podem se tornar institucionalizadas de modo estável --, muitas vezes não são ideais para as elites e são, portanto, alvo de resistência9 . Isso significa que um elemento-chave

\footnotetext{
${ }^{9}$ A ideia básica aqui é que existem equilíbrios institucionais múltiplos dentro do capitalismo, e todos são funcionalmente compatíveis com o capitalismo (ou seja, contribuem para a resolução de problemas da reprodução capitalista), mas alguns são melhores para os capitalistas do que outros e alguns envolvem mais empoderamento social do que outros. Uma transformação simbiótica busca amplia o empoderamento social, enquanto almeja alcançar um equilíbrio institucional que contribui para que o capitalismo funcione bem. Isso muitas vezes requer o bloqueio da solução preferida pelos capitalistas. Como Joel Rogers colocou, para fazer com que os capitalistas aceitem um caminho eficiente é preciso fechar o caminho do lucro selvagem. Para uma discussão detalhada desse complexo conjunto de compromissos e condições de equilíbrio, ver Wright (2010: cap. 11).
}

das estratégias rupturais -- confrontos entre forças sociais organizadas opostas, em que há vencedores e perdedores, vitórias e derrotas -- será uma parte de qualquer trajetória sustentável de empoderamento social. O propósito de tais confrontos, no entanto, não é uma ruptura sistêmica com a dominação capitalista, mas criar mais espaço para a interação de estratégias intersticiais e simbióticas.

\section{Conclusão}

O modelo proposto aqui, de um socialismo enraizado no empoderamento social, envolve um compromisso com o pluralismo institucional e a heterogeneidade. Em vez de um projeto unitário institucional para transcender o capitalismo, as configurações de empoderamento social, abrem espaço para uma ampla diversidade de formas institucionais. Cooperativas de trabalhadores e projetos locais de economia social, bancos e empresas estatais, regulação social democrática das empresas, crédito solidário e orçamento participativo minam todos, potencialmente, a dominação do capitalismo e aumentam o peso do poder social dentro do híbrido econômico.

A necessidade de pluralismo institucional sugere a possibilidade de níveis maiores de respeito e cooperação entre diferentes tradições políticas de anticapitalismo. Historicamente, essas tradições viram-se como rivais e, claro, num sentido importante o foram de fato: competiram por corações e mentes dos potenciais adeptos, assim como pelos recursos materiais com os quais pudessem avançar em seus objetivos. Mas se considerarmos essas alternativas como empurrando, cada uma a seu modo, uma dimensão diferente das configurações institucionais de uma alternativa emancipatória ao capitalismo, então há, pelo menos, algum espaço para vê-las como complementares, não antagônicas.

O pluralismo institucional do destino também sugere pluralismo estratégico nas práticas de transformação. Dentro de algumas dessas configurações, para fortalecer o poder social requer o poder estatal. Mas outras configurações podem avançar mesmo sem o poder estatal. Isto é especialmente verdadeiro para algumas das iniciativas de economia social -- cooperativas de trabalhadores, agricultura urbana comunitária, crédito solidário, posse fundiária comunitária etc. Ativistas de esquerda, especialmente na esquerda radical, muitas vezes consideraram esses tipos de iniciativas com orientação local e comunitárias como não sendo muito "políticas", uma vez que não envolvem sempre um confronto direto com o poder político. Esta é uma visão estreita da política, na minha opinião. Estratégias intersticiais envolvem mostrar 
que outro mundo é possível construindo-o nos espaços disponíveis e, em seguida, pressionando o Estado e as políticas públicas para ampliar esses espaços. Para muitas pessoas esses tipos de iniciativas intersticiais também têm a vantagem de gerar resultados imediatos e tangíveis em que a contribuição de cada pessoa claramente importa. A esquerda que está ancorada no problema multidimensional e multiescalar de aprofundar a democracia pode abranger essa vasta gama de estratégias e projetos de transformação. E na medida em que a democracia é um valor central na maioria das sociedades capitalistas desenvolvidas -- simbólica e substantivamente -- a esquerda ancorada em um amplo projeto democrático pode também estar melhor posicionada para sair de seu isolamento da política dominante.

\section{Referências}

Offe, Claus. 1974. Structural Problems of the Capitalist State: Class rule and the political system. On the selectiveness of political institutions. In V. Beyme (ed.), German Political Studies, v. I. Londres: Sage, p. 31-54.

Therborn, Göran. 1978. What Does the Ruling Class Do When It Rules? Londres: New Left Books.

Wright, Erik. 2006. Compass Points: Towards a Socialist Alternative. New Left Review 41.

Wright, Erik. 2010. Envisioning Real Utopias. Londres: Verso. 